\title{
Status and Prospect of Research on Juncao Opener
}

\author{
Shuhe ZHENG $^{1, a}$, Wei YANG ${ }^{2, b}$ \\ ${ }^{1}$ Fujian Agriculture and Forestry University, Fuzhou ,Fujian,350002, China \\ ${ }^{2}$ Fujian Agriculture and Forestry University, Fuzhou ,Fujian,350002, China \\ azshld1998@163.com,b472574177@qq.com
}

\begin{abstract}
Keywords: Giant juncao; Opener ; Planter; Prospect
Abstract. The opener is the important part of planter, which can affect the accuracy of planting, seed emergence rate and situation of seed after fell in the seedbed. This paper summaries the type of openers at home and abroad, and the characteristics of each kind of opener and suitable places are analyzed. Because of the inapposite ditch and seed level, and the seed will move by using the present opener during no-till planting, that can be also caused low seed emergence rate ,low planting efficiency and inconsistency distributed. In order to solve those problems, giant juncao opener including width and depth of the adjustment, fertilization function and profiling ability was designed.
\end{abstract}

\section{Introduction}

Juncao was introduced to China by Zhanxi Lin in 1983, after years of research, the field has been extended to mushroom culture-medium, soil and water conservation, sand control, Animal husbandry feed ,biomass new energy and so on. Our country owns the independent intellectual property rights and the international leading integrated technology of Juncao, the worldwide problem of "bacteria forest contradiction" is solved effectively[1]. As the important component of planter, opener according to the different agronomic requirements, opened corresponding ditch and guide the seeds to fall. The seeds distribution state and emergence rate, and the balance, stability and energy consumption of the whole machine are affected by the performance of opener[2-3]. The furrow width is $5 \mathrm{~cm} \sim 10 \mathrm{~cm}$, furrow depth is $6 \mathrm{~cm} \sim 9 \mathrm{~cm}$ and thickness of covering soil of $2 \mathrm{~cm} \sim 5 \mathrm{~cm}$, and the fertilizer must be fall before seeding. This paper summarized two types of commonly used openers--rolling opener and mobile opener, analyzed the range of application, pointed out the main problems during working, designed a set of ditching, width and depth of the adjustment, fertilizing, planting and profiling as one of the opener

\section{Rolling Opener}

One Disk Opener.The working part of opener is a spherical disk (Fig.1), the soil is cut out of the oval ditch following the rolled disk and the seed falls along the surface to the seed bed during the ditching operation[4]. The one dick opener has excellent penetration abilities and light weight, but the soil is disturbed, influenced soil moisture content, the ditch is narrower and not flat. So it is not suitable for arid areas and precision seeding.

Shouqin Zhang [5-7] analyzed opener force by computer simulation, resolved the interaction of one disk opener and soil into lateral earth-moving resistance and rolling earth-moving resistance. The opener surface force was showed as Fig.2. So, the equation of the force was, 


$$
F=\iint e d A+\iint f d A+\iint q d
$$

Can be simplified to,

$$
F=N+T+Q
$$

Among them, $N=\iint e d A, T=\iint f d A, Q=\iint q d l$, where e is surface normal stress, $\mathrm{f}$ is Shear stress, $\mathrm{q}$ is resultant of normal stress and shear stress, 1 is furrow width, $\mathrm{A}$ is surface area of opener, $\mathrm{N}$ is soil-engaging normal stress, the main reason of soil sway which overcome the interface resistance of soil disturbance or not. $\mathrm{T}$ is shear stress of relative motion between soil and opener, $\mathrm{Q}$ is penetration resistance.

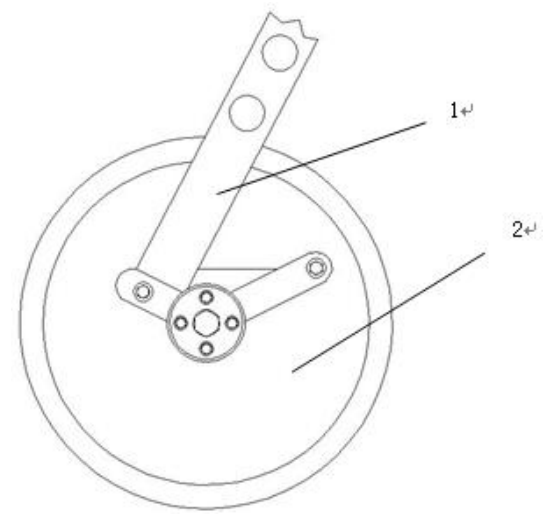

1. connecting bar 2.one disk

Fig.1 One disk opener

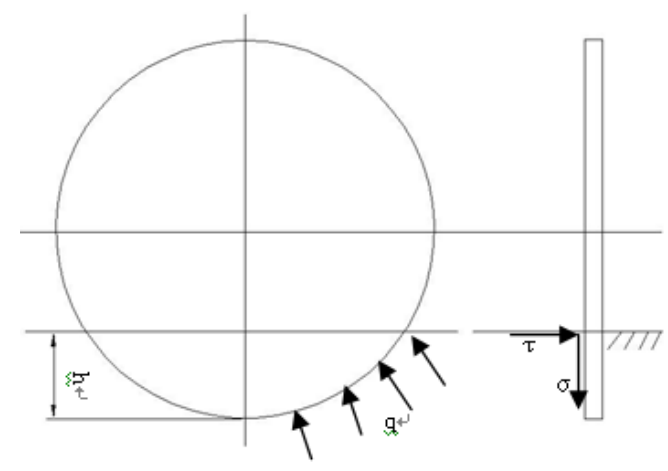

Fig.2 One disk opener body diagram

The results showed that the normal stress and shear stress of opener increases with the increasing of disk angle, furrow depth and soil moisture content. The soil resistant force decreases with the increasing of soil moisture content .The equation (2) showed the mutual regulations among opener force parts and soil moisture content, disk angle and furrow depth.

Double Disk Opener.The working parts of double disk opener (Fig.3) are composed of two flat disks, inclined to each other and intersecting at one point. The opener depends on the whole weight of the planter and spring pressure to ditch, the roots have been cut off and the soil was squeezed side to side during the ditching operation. Double disk opener has strong penetration performance, even if in the condition that have many toots, weeds and damp soil are still working well. The longitudinal stability is poorer because the complicated structures ,high manufacturing costs, and great spring pressure to enter the soil, so the opener is often used in the big not-till seeding machine, grain drill and row-crop seeding machine. 


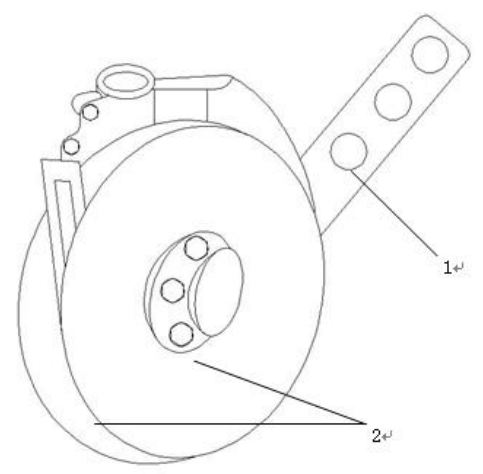

1.double disk 2. connecting bar

Fig.3 Double disk opener

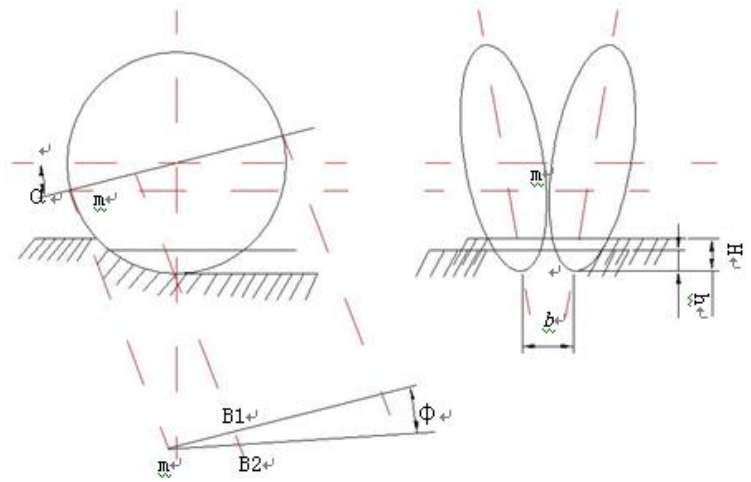

Fig.4 Body diagram

Bahri and Bansal[8] do an experiment to evaluate the performance of different opener. The results showed that to use a combination device consisting of double disk opener and roller on wet and loose soil to ditch, the performance was best. Huichun Yu [9-10] et al. analyzed different type furrow under different parameters by computer simulation. The different parameters were showed in Fig.4, the mathematical model for calculating the different parameters was established. the equation of the furrow width $b$ was assumed as:

$$
b=B_{1} B_{2}=2 m B_{2} \sin (\varphi / 2) .
$$

$$
m B_{2}=D(1-\sin \alpha) / 2 .
$$

The formula can be derived as below,

$$
b=D(1-\sin \alpha) \sin (\varphi / 2) .
$$

Where $D$ is the disk diameter, $\alpha$ is the angle between the horizontal line and disk intersection point, $\varphi$ is the angle between the two disks , $m$ is the disk intersection point.

The equation of the ridge convexity $h$ was assumed as:

$$
h=\beta H \text {. }
$$

Where $H$ is the depth, $\beta$ is the coefficient of soil landslide $(\beta \leq 1)$.

The analyze showed that the ridge convexity and the flatness of the furrow bottom can be changed by inflect the disk diameter $(D)$, the disk intersection point $(m)$, the angle between the horizontal line and disk intersection point $(\alpha)$ and the angle between the two disks $(\varphi)$.

\section{Mobile Opener}

Sliding-knife Opener.The sliding-knife opener (Fig.5) is commonly used. The opener depends on the weight and spring pressure to ditch, the soil was squeezed side to side and the soil was squeezed into a furrow, the furrow depth can be adjust by spring pressure. The opener has small soil disturbance, strong conserve moisture ability, and the dry soil and wet soil are not mixed. So, when ditching, the event distribution of seeds and the consistency of deep seeding in the field are favorable. otherwise, the root development is impeded by the seedbed quality of large soil cone 
index, and the opener has large soil resistant force,therefore, it is not suitable for high-speed operations. At present, the opener used primarily for corn, cotton and other crops on the planter.

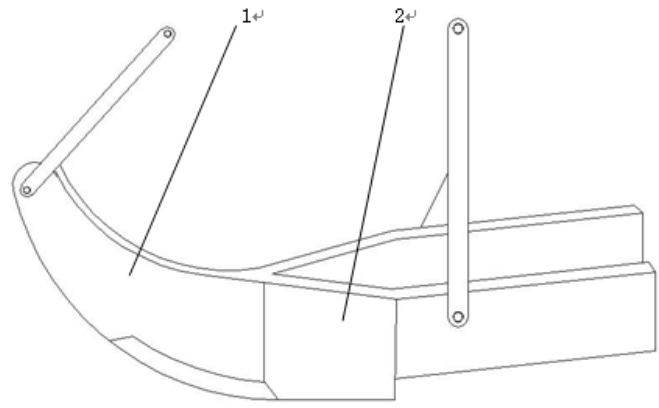

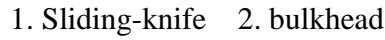

Fig.5 Sliding-knife opener

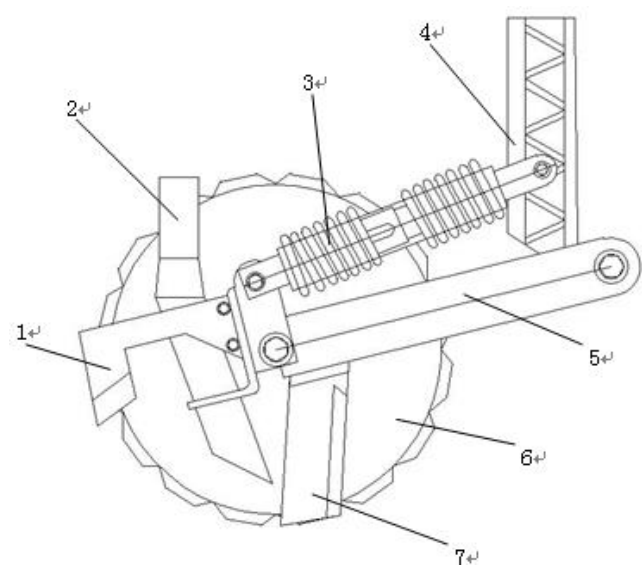

1. scraper 2. fertilizer tube 3. spring arrangement

4. fertilizer shaft 5. lever 6. Sliding-knife-type disk

7. profiling knife

Fig.6 Sliding-knife-type opener

Damora D[11] and Tessier[12] et al. concluded that cutting resistant force of the sliding-knife opener decreases with the increasing of slip angle, and decreases with the decreasing of friction angle by experiments. To sliding-knife opener, the sliding-knife shapes designed for the curve is more effort than the straight line. Di yingkai et al. designed a sliding-knife opener (Fig.6) with combination structure characteristic of disk opener and slide-knife opener. The interaction of sliding-knife-type disk opener and soil were simulated by LS-DYNA module of ANSYS, the results of field trials showed that sliding-knife-type disk opener had excellent buried and broken stubble abilities[13-15].To improve the seedbed quality and enhance the even distribution of soybean seeds and the consistency of deep seeding in the field ,and targeting the double-row high-yield planting techniques on soybean ridges, Honglei Jia [16-17]et al. manufactured the profiling sliding-knife openers that could dig out $\mathrm{V}$-shaped seed furrows and function as single profiling based on a self-invented double-V shape opener, show as Fig.7. The profiling sliding-knife opener is composed of connection bar, soil-compressing profiling wheels, profiling device, squeezing knife, and sliding-knife, it can build favorable seedbeds, mainly functions to dig out V-shaped seed furrows, guarantee the consistency of furrowing depths and the even distribution of seeds.

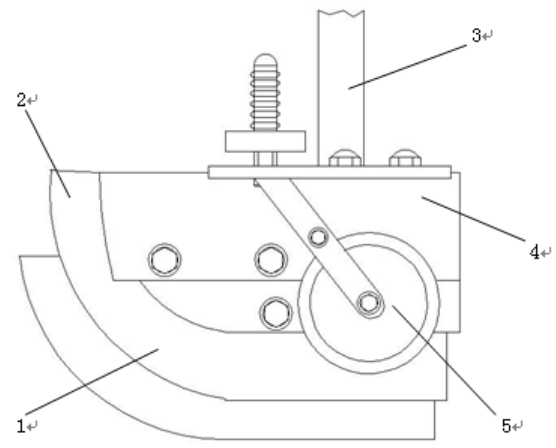


Core Ploughshare Opener. Figure. 8 is a schematic drawing that illustrates the core ploughshare opener. In the ridge area of northeast region of China, the core ploughshare type furrow opener is widely used, which is with simple structure, flat ditch, better buried performance, and less demanding on soil preparation before planting. However, the furrow opener is ditching too large width with poor soil moisture and the large passage of lateral soil during ditching, so is not suitable for high-speed seeding[18].

Traditional furrow openers are lack of the ability of reducing resistance and clay adhesion, in order to solve this problem, Haiyun Ma [19] designed a new bionic opener which based on characteristics of adhesion and resistance reduction of soil animals and ultra-high molecular weight polyethylene. And designed a set of field experiment, showed that clay adhesion on the traditional opener was not found when soil humidity was less than $9 \%$, but obvious when soil humidity was more than $20.8 \%$, while the adhesion on the bionic opener was little regardless of soil humidity. Furthermore, the bionic opener could work best in an optimal condition with soil moisture of $16.3 \%$, the trenching depth of $6 \mathrm{~cm}$ and the forward velocity of $1.8 \mathrm{~km} / \mathrm{h}$.

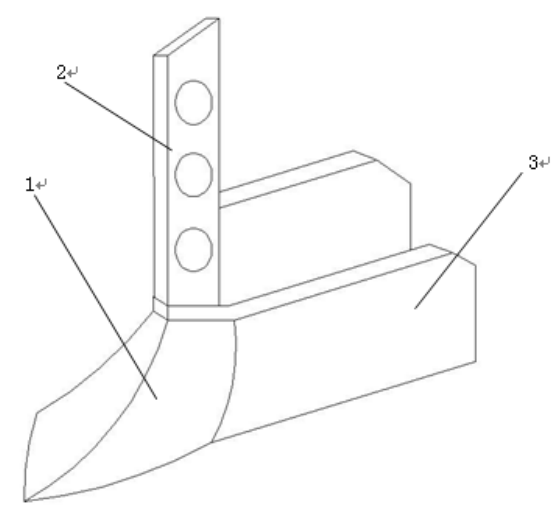

1. plough body 2. connecting bar 3. scraper

Fig.8 Core ploughshare opener

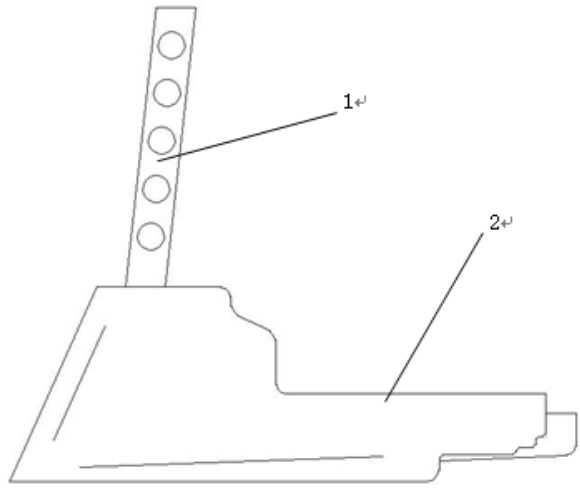

1. connecting bar 2. plough body

Fig.9 Boat opener

Boat Opener.Most of the penetrating angle and cutting angle of boat opener (Fig.9) are fixed value, that are $60^{\circ}$ and $35^{\circ}$ respectively. The opener can form a "V-type" and flat ditch depends on the whole weight of the planter, user can select single, double and three lines of open ditch according to the need, each opener can ditch one, two or three kinds of ditch, the opener is capable the narrow row seeding and precision seeding requirements. But the opener working speed should not be too high, the maximum of speed is $7 \mathrm{~km} / \mathrm{h}$. In the planter of vegetables, sugar beets, and cereal - leguminous crops, the boat opener is widely used, which owns simple structure.

Abernathy and Porterfield[23] et al. designed a soil bin with light sandy soil to be experiment platform, the experiment showed that the best range of penetration angle of boat opener is $90^{\circ} \sim 150^{\circ}$ and the cutting angle is $15^{\circ} \sim 60^{\circ}$, at the same time to draw a larger chamfered angle and wedge angle is more conducive to ditch.

Hoe Shovel Opener.Hoe shovel opener (Fig.10) is a typical acute angle opener, depends on the whole weight of the planter and traction to ditch. The opener has a tendency into the soil because of the small penetration angle, The soil is turned up along the front of the opener, the soil was squeezed side to side and the soil was squeezed into a furrow. The Hoe shovel opener is widely used, which is with simple structure, light weight and better buried performance, however, the bottom of the soil will turned up, making dry and wet soil mixed, water storage and retention was decreased during ditch, so it is not suitable for dry areas[24-25]. And the quality of work is unstable, the 
opener will be chinked by the hanging grass, plug and so on.

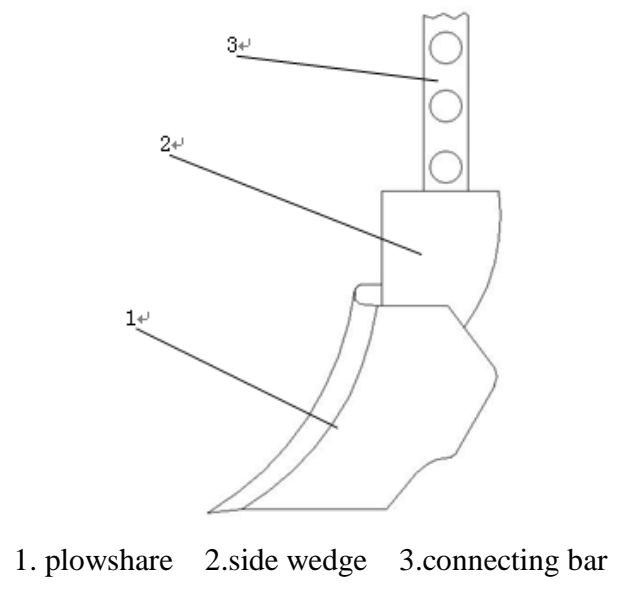

Fig.10 Hoe shovel opener

Zonglu Yao et al.[26] designed and manufactured different openers including different penetration angle, penetration clearance angle and side wedge. The soil resistant force and situation of surface after opened groove were measured in the soil bin. The results showed the influences of penetration angle and penetration clearance angle were significant for soil resistant force and no significant for side force and upright force. The low values of soil resistant force were observed at $5^{\circ}$ of penetration clearance angle.

\section{Problems of Opener}

Region Problems.At present, Juncao are widely cultivated in Fujian, Hebei and Xinjiang [27]. Hebei receives little rain in spring, in summer of high temperature and rainfall, and in autumn is glorious. Requires the ditch depth of about $10 \mathrm{~cm}$, need to watering after covered immediately; Xinjiang is a typical dry continental climate with severe winters, and has a large temperature difference between day and night and sunshine, requires the furrow depth is about $20 \mathrm{~cm}$, and thickness of covering soil of $3 \mathrm{~cm}-5 \mathrm{~cm}$; Fujian with abundant light supply and rainfall ,is one of the most abundant rainfall in China. Requires the furrow width is $5 \mathrm{~cm}-10 \mathrm{~cm}$, furrow depth is $6 \mathrm{~cm}-9 \mathrm{~cm}$ and thickness of covering soil of $2 \mathrm{~cm}-5 \mathrm{~cm}$, and the fertilizer must be fall before seeding. The climate and geographical environment of these areas are quite different, and requires the different amount of furrow depth, furrow width, thickness of covering soil, soil moisture and fertilization. But at present, the design of opener is not in accordance with the different agronomic requirements of different regions. During the planting process, using traditional opener has a large difference in the planting requirements of planting areas ,that making the seed germination rate very low, not only lead to low planting efficiency, planting costs are also higher.

Root Growth Rate Problems.At present, most of the opener penetration angle is larger and is not easy to ditch, the power consumption of the opener is increases with the increasing of penetration angle. The furrow width and depth is too large, and the opener without side wedge. So the furrow depth is too deep, making dry and wet soil mix and water storage and retention was decreased during ditch, and the root development is impeded by the seedbed quality of large soil cone index[28], and the seed were moved by opener during planting, hinder the event distribution. 
Furrow Depth and Width Problems.The profile ability and shock capacity are both poor, because of the majority of the opener and the rack are connected by welding and bolts, during ditching, the furrow depth is not uniform and the furrow type is inconsistent, resulted the Juncao growth conditions are inconsistent which is planted on the same stage, and it is not conducive to post-management, and also increased labor costs.

\section{Design of Juncao Opener}

According to the existing problems of the opener, combined with the requirements of the cultivation of agronomic grass in the Fujian area, and based on the existing knife-type opener, proposed a set of ditching, width and depth of the adjustment, fertilizing, planting and profiling as one of the opener (Fig.11). The opener consists of sliding-knife, fertilizer tube, side wedge, regulating plate, and profiling wheel. With the sliding-knife cutting open the soil, the soil was squeezed side to side and was squeezed into a furrow by side wedge, then fertilizers fall from the fertilizer tube to the bottom of the ditch, finally the seeds fall from the side wedge.

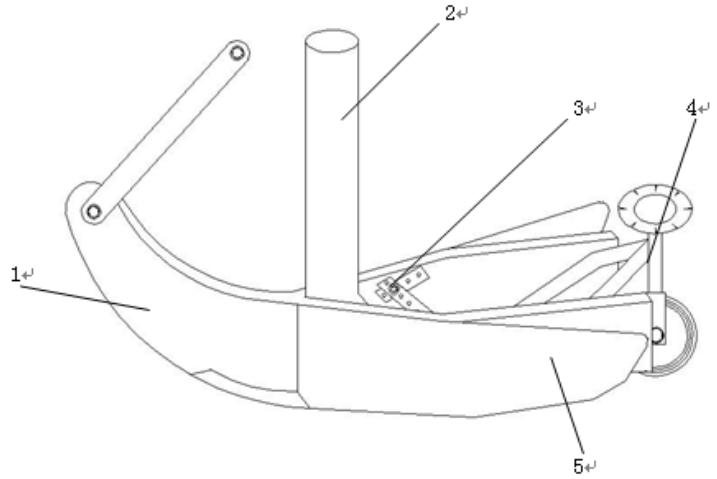

1.sliding-knife 2.fetilizer tube 3. regulating plate

4. profiling wheel 5.side wedg

Fig.11.Adjustable sliding-knife opener

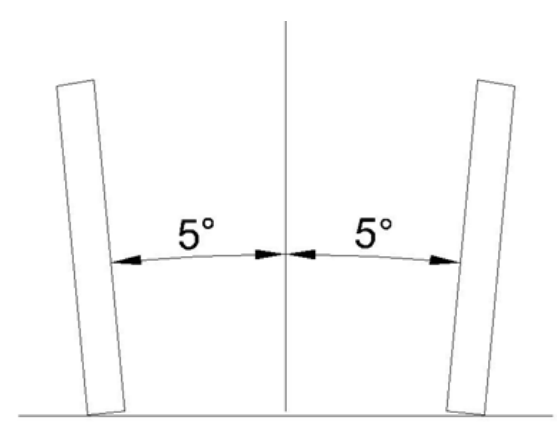

Fig.12 The angle between the opener tial and the vertical plane

Furrow Depth and Width Adjustable.At present, the width and depth of opener which was used in Juncao planter is not adjustable, in order to solve this problem, a regulating plate(As shown in Figure 5, component 5) is added to the opener. The adjustment plate is hinged with the opener, achieving the furrow width adjustable by using bolts which connected the plate holes, the opener and the rack are connected by bolts can achieving the furrow width adjustable, and is easy to replace the different types of opener.

Fertilization and Profiling .According to the agronomic requirements of Juncao that need to fertilize in the bottom before seedlings, so add fertilizer tube on the opener that can achieve fertilization function, as shown in Figure 11, component 3. It is conducted to seeding growth that fertilize in the bottom before seedlings. To improve the event distribution of Juncao seeds and the consistency of deep seeding in the field, developed a profiling wheel that could adjust the height according to the different surface condition, which can be used to improve the profiling capacity of the opener[29].

The Design of Side Wedge and Bottom.In order to improve the seedbed quality, the side wedge length of opener were increased, as shown in Figure 11, component 4, reducing the mixing of dry and wet soil effectively.To improve the root generation rate, the bottom of the opener were designed 
into an irregular shape with a slightly serrated border, that can be reduced the force of the bottom and soil, and make loose soil. As shown in Figure 12, the inclination of the side face of opener and the vertical plane was designed into 5o,that can be ditched the " $\mathrm{V}$ " type flat furrow, decreases the bunches of seeds, and enhances the homogeneity of the sowing[30-32].

\section{Conclusion}

The typical types of openers used at home and abroad were induced, and the characteristics of each kind of opener and suitable places were analyzed. In order to solve the problem of low homogeneity and low germination rate at present, A opener including width and depth of the adjustment, fertilization function and profiling ability was developed, which based on the existing research on the opener, combined with the requirements of the cultivation of giant grass. The depth and width are designed to be adjustable according to different areas of the different agronomic requirements. Added the fertilization function to improve the seedbed quality and seeding growth; Added a profiling wheel to enhance the event distribution of Juncao seeds and the consistency of deep seeding in the field.

\section{Acknowledgements}

This paper was based on research supported by Natural Science Foundation of Fujian Province(2016J01209) and the Scientific and Technological Project of National Engineering Research Center of Juncao Technology(K80ND800203). These supports are greatly appreciated. The authors also thank the reviewers for their self-giving contributions and valuable comments.

\section{References}

[1] LIN Xinsheng.LIN Zhanxi. Preliminary study on Juncao as biomass fuel[N].Journal of Fujian College of Forestry,2013,33(1):82-86.

[2] PAN Shiqiang.Research on the Optimization Design and the Experiment of the Core Ploughshare Furrow Opener Based on the Discrete Element Method[D],Changchun, Jilin University,2015.

[3] Murray J R, Tullberg J N, Basnet B B.Planters and their components [M]. Canberra Australian Centre for International Agricultural Research,2006.

[4] ZHANG Xirui, HE Jin.Design and experiment on the driving disc of anti-blocking unit foe no-tillage planter[J].Transactions of the CSAE,2009,29(9):117-121.

[5] ZHANG Shouqin, MA Xu.Forces Acting on Disk Colter and Computer Simulation[J]. Transactions of the CSAE,1995,11(4):52-56.

[6] ZUO Chunsheng, ZHANG Shouqin.The study on the adhesion-decreasing and resistant-reducing of disc opener[J], Transactions of the Chinese Society of Agricultural Machinery, 1997, 28:37-40.

[7] ZHANG Shouqin,. The study on the model of disk coulter force[J]. Transactions of the Chinese Society of Agricultural Machinery,1998,29:67-71.

[8] Bahri A; Bansal R K.Evaluation of different combination of furrow openers and press wheels for no till seeding[J]. Agricultural Engineering, Abstracts, 1993,18(6),226.

[9] YU Huichun, LIU Junfeng. Simulation study on the property and motion of the double-disk digger[N].Journal of Agriculture university of Hebei, 2004,27(1):108-110. 
[10] Shmulevich I,Asaf Z,Rubinstein D. Interaction between soil and a wide cutting blade using the discrete element method. Soil \& Tillage Research, 2007, 97: 37-50

[11] Damora D, Pandey K P .Evaluation of performance of furrow openers of combined seed and fertilizer drills [J].Soil and Tillage Research , 1995, 34(1):127-139.

[12] Tessier S, Saxton K E, Papendick R I, etal.Zero tillage furrow opener effects on seed environment and wheat emergence[J].Soil\&Tillage Research, 1991, 21(34):347-360.

[13] DI Yingkai. Design and Experiment of Sliding-Knife Notched Disc Opener[D].Changchun,Jilin University,2013.

[14] WANG Qingjie,YAO Zonglu.Design and Experiment on a wedge shaped no-tillage opener[J].Chinese journal of mechanical engineering,2008,44(9): 177-182.

[15] Karmakara S.,Kushwaha R.L.Lague ,Numerical modeling of soil stress and pressure distribution on a flat tillage tool using computational fluid dynamics[J].Biosystems Engineering,2007,97(1):407-414.

[16] JIA Honglei,ZHENG Jiaixin. Design and experiment of profiling sliding-knife opener[J].Transactions of the Chinese Society of Agricultural Engineering. 2017.33(4): 16-24.

[17] JIA Honglei,WANG Gang.Design and Experiment of 1GH-3 Inter-row Tillage Machine[J]. Transactions of the Chinese Society of Agricultural Machinery, 2012, 43(6) : 35-41.

[18] PAN Shiqiang, CAO Zifu.The Design of Furrow Opener Based on Discrete Element Method[J]. Journal of Agricultural Mechanization Research, .2016, 9 (9): 23-27.

[19] MA Yunhai,MA Shengsheng. Measurement and analysis on reducing adhesion and resistance of bionic ripple opener[J].Transactions of the Chinese Society of Agricultural Engineering, 2014,30(5):36-39.

[20] ZHAO Shuhong,JIANG Encheng. Design and motion simulation of opener with bidirectional parallelogram linkage profiling mechanism on wheat seeder[J], Transactions of the CSAE, 2013, 29(14): 26-32.

[21] LIU Guomin,ZOU Meng. Interfacial dynamics simulation between soil and earthworm surface[N].Journal of Jilin University(Engineering and Technology Edition).2010，40(6):1609 $-1613$.

[22] Solhjou A, Fielke J M, Desbiolles J M A, et al. Soil translocation by narrow openers with various bent leg geometries[J]. Biosystems Engineering, 2014, 127(3): 41-49.

[23] Abernathy G H;Porterfield J G; Effect of planter openers shape on furrow characteristics [J]. Transactions of ASAE, 1969,12(1): 16 - 19.

[24] WANG Qihao,BU Ku.Structure Analysis of the Large No-till Seeder Openers[J].Journal of Agricultural Mechanization Research, 2012,3 (4): 45-48.

[25] Barr,James B.et al. Minimising soil disturbance and reaction forces for high speed sowing using bentleg furrow openers[J]. Biosystems Engineering, 2016, 151(1): 53-64.

[26] YAO Zonglu.Effect of different structural no-till openers on soil resistant force[J]. Journal of Agricultural Mechanization Research, 2009, 7 (7):30-34.

[27] LI Jun, The project plan of Moringa Oleifera planting base[D].Cheng du,Southwest jiaotong university,2013.

[28] Zhang,Xiangcai,Li,Hongwen,et al.Effect of tine furrow opener on soil disturbance, draught,and fuel consumption[J].International Agricultural Engineering Journal, 2016,25(3):29-45.

[29] LI Hui,WU Jianmin. Experimental study and design on furrow opener of vertical stratified application of fertilizer and seed[N]. 2013,45(2): 143-146.

[30] Barr, James, et al. Discrete element modelling of narrow point openers to improve soil 
disturbance characteristics of no-till seeding systems[J].2016 American Society of Agricultural and Biological Engineers Annual International Meeting. ISBN-13;

[31] D.Karayel,A.Özmerzi.Comparison of vertical and lateral seed distribution of furrow openers using a new criterion[J]. Soil \& Tillage Research .2006(1).

[32] Singh K P, Agrawal K N, Jat D, et al. Design, development and evaluation of furrow opener for differential depth fertilizer application[J]. Indian Journal of Agricultural Sciences, 2016, 86(2): $250-255$. 